\title{
Molecular Mechanism for the Hofmeister Effect Derived from NMR and DSC Measurements on Barnase
}

Jordan W. Bye, ${ }^{* \dagger}$ Nicola J. Baxter, ${ }^{*}{ }^{\ddagger}$ Andrea M. Hounslow, Robert J. Falconer, ${ }^{\dagger}$ and Mike P. Williamson*,

${ }^{\dagger}$ Department of Chemical and Biological Engineering, University of Sheffield, Sir Robert Hadfield Building, Mappin Street, Sheffield S1 3JD, U.K.

${ }^{\ddagger}$ Department of Molecular Biology and Biotechnology, Krebs Institute for Biomolecular Research, University of Sheffield, Firth Court, Western Bank, Sheffield S10 2TN, U.K.

Supporting Information

ABSTRACT: The effects of sodium thiocyanate, sodium chloride, and sodium sulfate on the ribonuclease barnase were studied using differential scanning calorimetry (DSC) and NMR. Both measurements reveal specific and saturable binding at low anion concentrations (up to $250 \mathrm{mM}$ ), which produces localized conformational and energetic effects that are unrelated to the Hofmeister series. The binding of sulfate slows intramolecular motions, as revealed by peak broadening in ${ }^{13} \mathrm{C}$ heteronuclear single quantum coherence spectroscopy. None of the anions shows significant binding to hydrophobic groups. Above $250 \mathrm{mM}$, the DSC results are consistent with the expected Hofmeister effects in that the chaotropic anion thiocyanate destabilizes barnase. In this higher concentration range, the anions have approximately linear effects on protein NMR chemical shifts, with no evidence for direct interaction of the anions with the protein surface. We conclude that the effects of the anions on barnase are mediated by solvent interactions. The results are not consistent with the predictions of the preferential interaction, preferential hydration, and excluded volume models commonly used to describe Hofmeister effects. Instead, they suggest that the Hofmeister anion effects on both stability and solubility of barnase are due to the way in which the protein interacts with water molecules, and in particular with water dipoles, which are more ordered around sulfate anions and less ordered around thiocyanate anions.

\section{INTRODUCTION}

Solutes are known to influence the physical properties of water, such as surface tension and viscosity. ${ }^{1}$ They are also known to influence the properties of biological molecules, in particular their solubility and stability. ${ }^{2-5}$ The mechanisms underpinning solute effects have attracted the attention of researchers for over a century. The field was initiated by Franz Hofmeister who demonstrated the ability of various salts to influence the solubility of protein ensembles found in hen egg white. ${ }^{2,6}$ These effects were found to be consistent for a range of proteins, which allowed the salts to be ordered by the extent of their effect on solubility into the "Hofmeister Series", given in Scheme 1 for the anions. Cations have much less effect compared to anions. ${ }^{3,7}$ In the 1960s, von Hippel demonstrated that protein stability was affected by the same Hofmeister ordering. ${ }^{3,4}$ Hofmeister effects have been shown to occur at moderate to high salt concentrations $(100-2000 \mathrm{mM}))^{2,7,8}$

A number of models have been developed to explain the molecular mechanism by which salts influence protein solubility and stability, but there is still no universally accepted model. ${ }^{5 a, c, 6,9}$ Understanding these mechanisms is particularly important for companies in the biotechnology sector who aim to develop formulations that maintain the stability, solubility, and activity of their biotherapeutics for prolonged periods. ${ }^{10}$ Hofmeister originally described the effects of salts on solubility in terms of their ability to "withdraw" water from the protein., Salts that withdrew water from the protein decreased solubility and those that were less able to withdraw water increased solubility. This developed into the water structure maker/ breaker theory in the 1930s, in which the higher charge density anions at the left of the series (kosmotropes) enhance the ordering of water and the lower charge density anions on the right (chaotropes) break it, leading to effects on both solubility and stability. ${ }^{\text {la }}$ This hypothesis has been challenged on the grounds that the large effects seen on protein solubility and stability could not be caused just by effects of the anions on the solvent, and that the expected effects on bulk solvent have not been observed, and the three most popular current theories are the preferential interaction, preferential hydration, and volume excluded effect models. ${ }^{11}$ In the first model, solubilizing/ destabilizing solutes (chaotropes) are described as preferentially interacting with the protein surface, which leads to a decrease in

Received: September 5, 2016

Accepted: October 10, 2016

Published: October 25, 2016 
Scheme 1. Hofmeister Series

$$
\begin{array}{lr}
\qquad \mathrm{PO}_{4}^{3-}>\mathrm{SO}_{4}{ }^{2-}>\mathrm{HPO}_{4}{ }^{2-}>\mathrm{F}^{-}>\mathrm{Cl}^{-}>\mathrm{NO}_{3}^{-}>\mathrm{Br}^{-}>\mathrm{ClO}_{3}^{-}>\mathrm{I}^{-}>\mathrm{ClO}_{4}^{-}>\mathrm{SCN}^{-} \\
\text {Increase in protein stability } & \text { Decrease in protein stability } \\
\text { Decrease in protein solubility } & \text { Increase in protein solubility }
\end{array}
$$

stability and an increase in solubility. ${ }^{5 e, 12,13}$ The other two models are similar to each other: precipitating/stabilizing solutes (kosmotropes) are said to be preferentially excluded from the protein surface (i.e., preferentially hydrated) where they exert an excluded volume effect, essentially by removing "free" water, thereby increasing stability and decreasing solubility. ${ }^{5 a, 13}$ Low charge density anions have been shown to associate with protein surface charges and screen proteinprotein interactions more effectively than high charge density anions. ${ }^{5 a}$ The extent to which low charge density anions prevent protein-protein interactions was found to correlate with their position in the Hofmeister series, adding support to the preferential interaction model. Low charge density (poorly hydrated) anions such as thiocyanate are believed to interact with surface-exposed hydrophobic residues and induce protein-protein interactions between positively charged proteins. It is believed that these interactions could explain Hofmeister effects for such anions, in contrast to the high charge density anions which have been shown not to interact with hydrophobic groups. ${ }^{14}$ NMR spectroscopy has been recently employed to study interactions between various Hofmeister salts, proteins, and synthetic peptides. ${ }^{9 f, 13,15,16}$ Findings from these experiments have suggested that low charge density anion (destabilizing/solubilizing) effects are mediated by their ability to interact with areas on the peptide backbone. The high charge density anion (stabilizing/ precipitating) effects are said to be caused by an excluded volume effect as these anions were not observed to interact with the peptide backbone. ${ }^{9 f, 13}$ On the other hand, it is noteworthy that the Hofmeister effect is not noticeably affected by protein concentration, ${ }^{17}$ which would be expected for the preferential interaction model.

Here, we studied the effects of three Hofmeister series salts: sodium thiocyanate (destabilizer/solubilizer), sodium chloride (neutral), and disodium sulfate (stabilizer/precipitator) on a catalytically inactive mutant of the Bacillus amyloliquefaciens ribonuclease barnase. ${ }^{18}$ Sodium was used as a common monovalent cation because it is generally considered to be a "neutral" ion, in the center of the cation Hofmeister series, and is observed to have little effect on protein solubility or stability. ${ }^{7,19}$ We used differential scanning calorimetry (DSC) to look at the effects on thermal stability, and multidimensional NMR spectroscopy to probe site-specific effects at backbone amides and carbonyls, as well as backbone and side chain $\mathrm{CH}$ groups. The results indicate that none of the three popular models is able to provide a satisfactory explanation of the data. We show that the anions, regardless of their position in the Hofmeister series, do interact with the protein surface, in similar places, but only at low concentrations $(<250 \mathrm{mM})$ where Hofmeister effects are still small and not dominating. Therefore, the preferential interaction model is invalid. At higher concentrations of up to $1 \mathrm{M}$, there is no observable increase in interactions with the protein surface for any of the anions, and there is no preferential interaction with hydrophobic groups, even for thiocyanate. This suggests that all of the anions exert their effects by altering the interaction of the protein with water: in other words, the preferential hydration and excluded volume effect models have elements of truth but are not fully consistent with the data. We propose a refinement of the structure maker/breaker model, based on a three-stage mechanism for the effects of anions previously proposed by the authors, ${ }^{7,8}$ in which at low concentrations, anions interact with the protein surface but have relatively small and site-specific effects on stability, whereas the Hofmeister effects at high anion concentrations are due to the stabilizers/precipitators organizing water dipoles around themselves and thus reducing the ability of water to solvate protein surfaces, whereas the destabilizers/solubilizers disrupt the organization of dipoles within bulk water and therefore allow the protein to be better solvated.

\section{EXPERIMENTAL SECTION}

Protein Expression, Purification, and Sample Preparation. All chemicals and enzymes were purchased from Sigma Aldrich. The catalytically inactive H102A mutant of $B$. amyloliquefaciens ribonuclease (barnase) was overexpressed in Escherichia coli M15 [pRep4] cells transformed with a pQE-60 plasmid using M9 minimal media supplemented with ${ }^{15} \mathrm{NH}_{4} \mathrm{Cl}$ and ${ }^{13} \mathrm{C}_{6}$-glucose (NMR sample) and was purified using $\mathrm{Q}$ sepharose and SP-sepharose ion exchange chromatography, as described. ${ }^{20}$ To minimize the presence of solutes, the samples were dialyzed extensively against ultrapure high-pressure liquid chromatography-grade water and the buffering capacity of barnase itself was used to maintain the $\mathrm{pH}$ of the sample, which was checked before each experiment and no substantial changes were observed. For the DSC experiments, the stock solution contained $1 \mathrm{mg} / \mathrm{mL}$ unlabeled barnase, $100 \% \mathrm{H}_{2} \mathrm{O}, \mathrm{pH} 6.5$, and for the NMR experiments, the stock solution comprised 0.5 $\mathrm{mM}{ }^{15} \mathrm{~N},{ }^{13} \mathrm{C}$ barnase, $10 \% \mathrm{D}_{2} \mathrm{O} / 90 \% \mathrm{H}_{2} \mathrm{O}, \mathrm{pH}$ 6.5. Both samples were stored at $-80{ }^{\circ} \mathrm{C}$ until required.

DSC Experiments. DSC experiments were conducted in a TA Instruments differential scanning calorimeter (Nano DSC; TA Instruments, New Castle, DE). The sample cell contained $40 \mu \mathrm{M}(0.5 \mathrm{mg} / \mathrm{mL})$ barnase, $\mathrm{pH} 6.5$, in the presence of $0-$ $1000 \mathrm{mM} \mathrm{NaSCN}, \mathrm{NaCl}$, or $\mathrm{Na}_{2} \mathrm{SO}_{4}$ with the reference cell containing the corresponding salt concentration with no protein. All samples were degassed on a degasser from TA Instruments for $60 \mathrm{~min}$ at $20^{\circ} \mathrm{C}$ before loading into the DSC. The DSC was equilibrated until the heat difference between the sample and reference cells was changing by $<0.003 \mu \mathrm{W} / \mathrm{s}$. All samples were run with a temperature range of $20-90{ }^{\circ} \mathrm{C}$ and heating rate of $1.5{ }^{\circ} \mathrm{C} / \mathrm{min}$; the sample and reference cell pressures were set to $3 \mathrm{~atm}$, and another prescan equilibration phase of $600 \mathrm{~s}$ occurred before heating. Data analysis was conducted with the NanoAnalyze software provided by the manufacturer. Ultrapure water baselines were subtracted from sample data using NanoAnalyze. The melting temperature $\left(T_{\mathrm{m}}\right)$ of barnase was taken to occur at the temperature with the maximum heat capacity. The reversibility of barnase unfolding was assessed under the experimental conditions given above, and it was found that barnase unfolding cannot be considered to be a two-state unfolding as only $60 \%$ of barnase refolded. For this reason, we did not include enthalpy and entropy data in the 
analysis. ${ }^{21}$ All concentrations for each salt tested were run in duplicate apart from the 50 and $750 \mathrm{mM}$ points.

NMR Experiments and Data Processing. All NMR spectra were acquired at $25{ }^{\circ} \mathrm{C}$ on an $800 \mathrm{MHz}$ Avance I Bruker spectrometer equipped with a room-temperature $5 \mathrm{~mm}$ probe and triple-axis gradients. Proton chemical shifts were referenced to 3-trimethylsilyl-2,2,3,3- $\left({ }^{2} \mathrm{H}_{4}\right)$ propionate (TSP, Sigma Aldrich) at $0.0 \mathrm{ppm} .{ }^{15} \mathrm{~N}$ and ${ }^{13} \mathrm{C}$ chemical shifts were calculated relative to TSP by using the gyromagnetic ratios of ${ }^{15} \mathrm{~N},{ }^{13} \mathrm{C}$, and ${ }^{1} \mathrm{H}$ nuclei $\left(\gamma\left({ }^{15} \mathrm{~N}\right) / \gamma\left({ }^{1} \mathrm{H}\right)=0.101329118\right.$ and $\left.\gamma\left({ }^{13} \mathrm{C}\right) / \gamma\left({ }^{1} \mathrm{H}\right)=0.251449530\right)$. Chemical shift values were obtained from entry 4964 in the BioMagResBank ${ }^{22}$ and were used to confirm resonance assignment of barnase using ${ }^{1} \mathrm{H},{ }^{15} \mathrm{~N}$ heteronuclear single quantum coherence (HSQC), ${ }^{1} \mathrm{H},{ }^{13} \mathrm{C}$ HSQC, three-dimensional (3D)-HNCO, 3D-HNCA, 3D $\mathrm{CCH}$-total correlation spectroscopy, and 3D HCCH-TOCSY experiments. The salt titration experiments were carried out separately in $3 \mathrm{~mm}$ NMR tubes (Norell) and used $0.5 \mathrm{mM}$ (0.33 mM for the $\mathrm{NaCl}$ titration) ${ }^{15} \mathrm{~N},{ }^{13} \mathrm{C}$ barnase, $10 \% \mathrm{D}_{2} \mathrm{O}$ / $90 \% \mathrm{H}_{2} \mathrm{O}, \mathrm{pH} 6.5$, and TSP at concentrations of $0,10,25,50$, $100,250,500,750$, and $1000 \mathrm{mM} \mathrm{NaSCN}, \mathrm{NaCl}$, or $\mathrm{Na}_{2} \mathrm{SO}_{4}$. Use of a $3 \mathrm{~mm}$ tube proved essential to avoid large losses in sensitivity and increases in pulse widths, which were recalibrated for each measurement. Barnase ${ }^{1} \mathrm{H},{ }^{15} \mathrm{~N}$, and ${ }^{13} \mathrm{C}$ chemical shifts were monitored by the acquisition of ${ }^{1} \mathrm{H},{ }^{15} \mathrm{~N}$ HSQC, ${ }^{1} \mathrm{H},{ }^{13} \mathrm{C}$ HSQC, and two-dimensional (2D) HNCO spectra using TopSpin 2.1 at each salt addition. Spectra were processed and peaks were assigned using the FELIX software (Felix NMR, Inc., San Diego, CA), and data were analyzed using home-written scripts running under Linux. Peak intensities were measured using the peak intensity (rather than the volume, which proved less reproducible), using identical acquisition and processing parameters (except pulse lengths). The solvent-accessible surface area was calculated from the PDB file 1a2p using the program naccess. Fitting to eq 1 followed a two-stage procedure. Chemical shift changes were first fitted to a simple linear equation (the first term of eq 1 ). Nuclei that fitted were classified as having linear shift changes. Nuclei that had poor fits $\left(\right.$ a $\chi^{2}$ value $\left.>20\right)$ were then fitted to the complete equation, using a home-written implementation of the Levenburg-Marquardt nonlinear least-squares fitting routine. Any nuclei that gave a $\chi^{2}$ value $<20$ in this fitting were

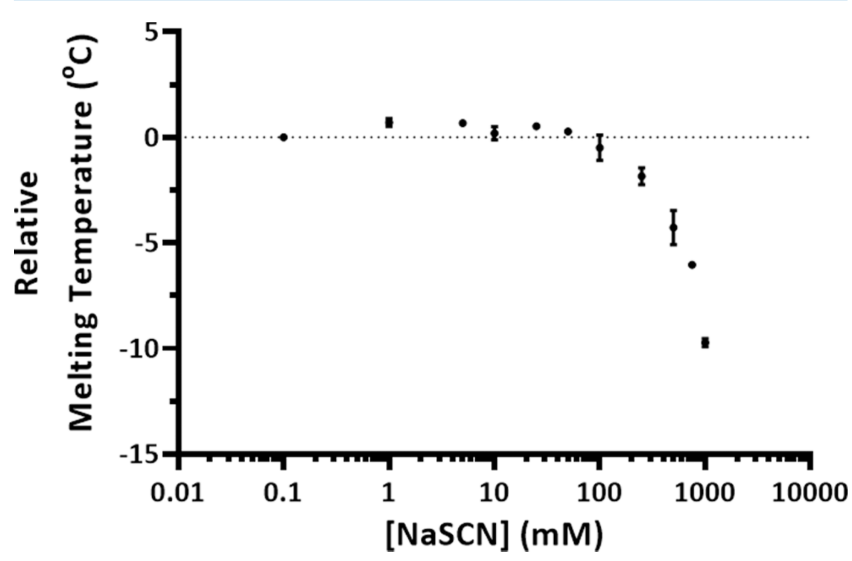

Figure 1. Change in melting temperature $\left(T_{\mathrm{m}}\right)$ of $0.5 \mathrm{mg} / \mathrm{mL}$ barnase in the presence of increasing sodium thiocyanate ( $\mathrm{NaSCN}$ ) concentration in ultrapure water at $\mathrm{pH}$ 6.5. Error bars are standard deviation $(n=2)$. Where no error bars are visible, they are contained within the data points. classified as having both curved and linear shift changes, while the rest were rejected.

\section{RESULTS}

DSC. The effect of thiocyanate on the thermal stability of H102A barnase was investigated using DSC (Figure 1) and has two distinct stages. The first stage occurs at concentrations $<100 \mathrm{mM}$ where thiocyanate anions have a slight but significant stabilizing effect on the protein. At around $100 \mathrm{mM}$, there is a clear transition as thiocyanate promotes significant destabiliza-
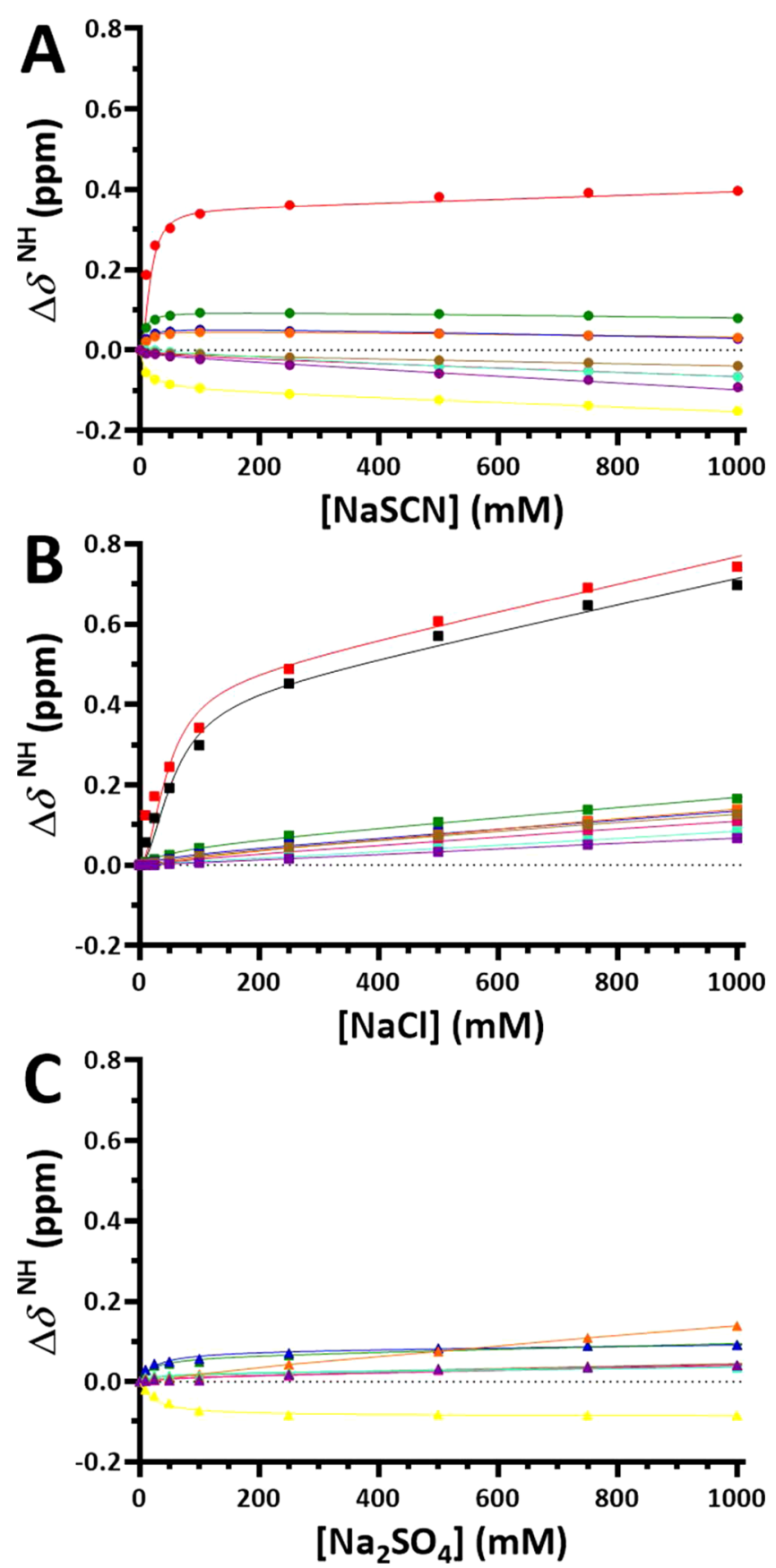

Figure 2. Chemical shift changes for backbone amide protons acquired from ${ }^{1} \mathrm{H}^{15} \mathrm{~N}$ HSQC spectra in the presence of (A) $\operatorname{NaSCN}(\bullet)$, (B) $\mathrm{NaCl}(\boldsymbol{\square})$, or $(\mathrm{C}) \mathrm{Na}_{2} \mathrm{SO}_{4}(\boldsymbol{\Delta})$. Symbols represent experimental data, and lines were generated from fitting to eq 1; Y24 (aqua), A30 (orange), A32 (brown), L42 (black), A43 (yellow), I51 (green), R83 (red), D86 (blue), K98 (pink), and T100 (purple). 
tion at higher anion concentrations, as expected from the Hofmeister series (DSC thermograms for each thiocyanate concentration tested are shown in Figure S1). The effects of chloride and sulfate on the thermal stability of barnase were also investigated (Figures S2 and S3). The thermograms at high chloride concentrations $(\geq 100 \mathrm{mM})$ and all concentrations of sulfate displayed signs of barnase aggregation. The profiles were less reproducible than that for thiocyanate, which is likely due to aggregation occurring before $T_{\mathrm{m}}$ is reached, and showed asymmetry with the downward slope after $T_{\mathrm{m}}$ having a steeper gradient than the upward curve (Figure S4). Protein aggregation is a characteristic of anions at the left end of the Hofmeister series, such as sulfate, and therefore this result is not surprising. Sulfate has a two-stage effect: at concentrations $<100 \mathrm{mM}$, there is no significant effect on $T_{\mathrm{m}}$, whereas above $100 \mathrm{mM}$, it has a significant stabilizing effect, in line with the Hofmeister series. Chloride effects a small but significant stabilization of barnase by about $0.7{ }^{\circ} \mathrm{C}$ up to $100 \mathrm{mM}$, but it has almost no effect at higher concentrations, as expected from its position in the Hofmeister series. In summary, although the
DSC results have limited scope, we can conclude that the effects of thiocyanate, chloride, and sulfate on barnase stability and probably also on solubility follow the Hofmeister series, but only at anion concentrations $>100 \mathrm{mM}$. Similar conclusions were reached in our previous studies. ${ }^{7,8}$

NMR Titrations: Overview. NMR chemical shifts of H102A barnase with increasing concentrations of thiocyanate, chloride, or sulfate were measured for backbone ${ }^{15} \mathrm{~N}$ and ${ }^{1} \mathrm{H}_{\mathrm{N}}$ nuclei (using ${ }^{1} \mathrm{H},{ }^{15} \mathrm{~N}$ HSQC spectra), backbone ${ }^{13} \mathrm{C}$ carbonyl nuclei (using 2D HNCO spectra), and aliphatic ${ }^{1} \mathrm{H}$ and ${ }^{13} \mathrm{C}$ nuclei (using ${ }^{1} \mathrm{H},{ }^{13} \mathrm{C}$ HSQC spectra). Approximately linear chemical shift changes with anion concentration were observed for most nuclei at concentrations from $250 \mathrm{mM}$ upward. However, many nuclei also showed curved chemical shift dependences at concentrations below about $250 \mathrm{mM}$, which display a variation in magnitude at different locations within barnase. Typical curves for a selection of amide protons (Y24, A30, A32, L42, A43, I51, R83, D86, K98, and T100) in the presence of thiocyanate, chloride, and sulfate are shown in Figure 2. The curved parts of the chemical shift profiles have
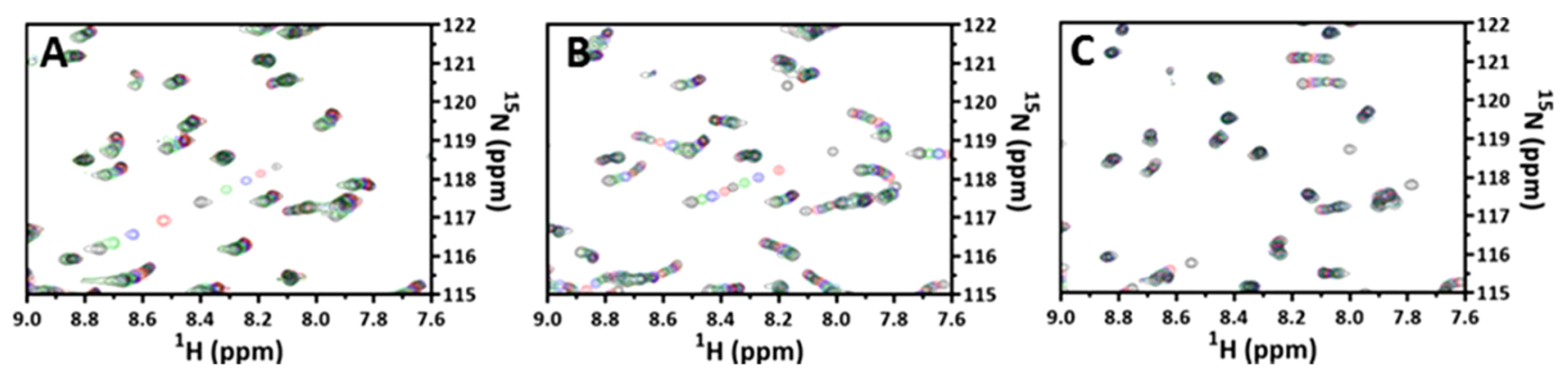

Figure 3. Expansions of a region in the ${ }^{1} \mathrm{H},{ }^{15} \mathrm{~N}$ HSQC spectrum of barnase in the presence of increasing concentrations of $(\mathrm{A}) \mathrm{NaSCN},(\mathrm{B}) \mathrm{NaCl}$, and (C) $\mathrm{Na}_{2} \mathrm{SO}_{4}$. Concentrations: 0 (black), 10 (red), 25 (blue), 50 (green), 100 (black), 250 (red), 500 (blue), 750 (green), and $1000 \mathrm{mM}$ (black).
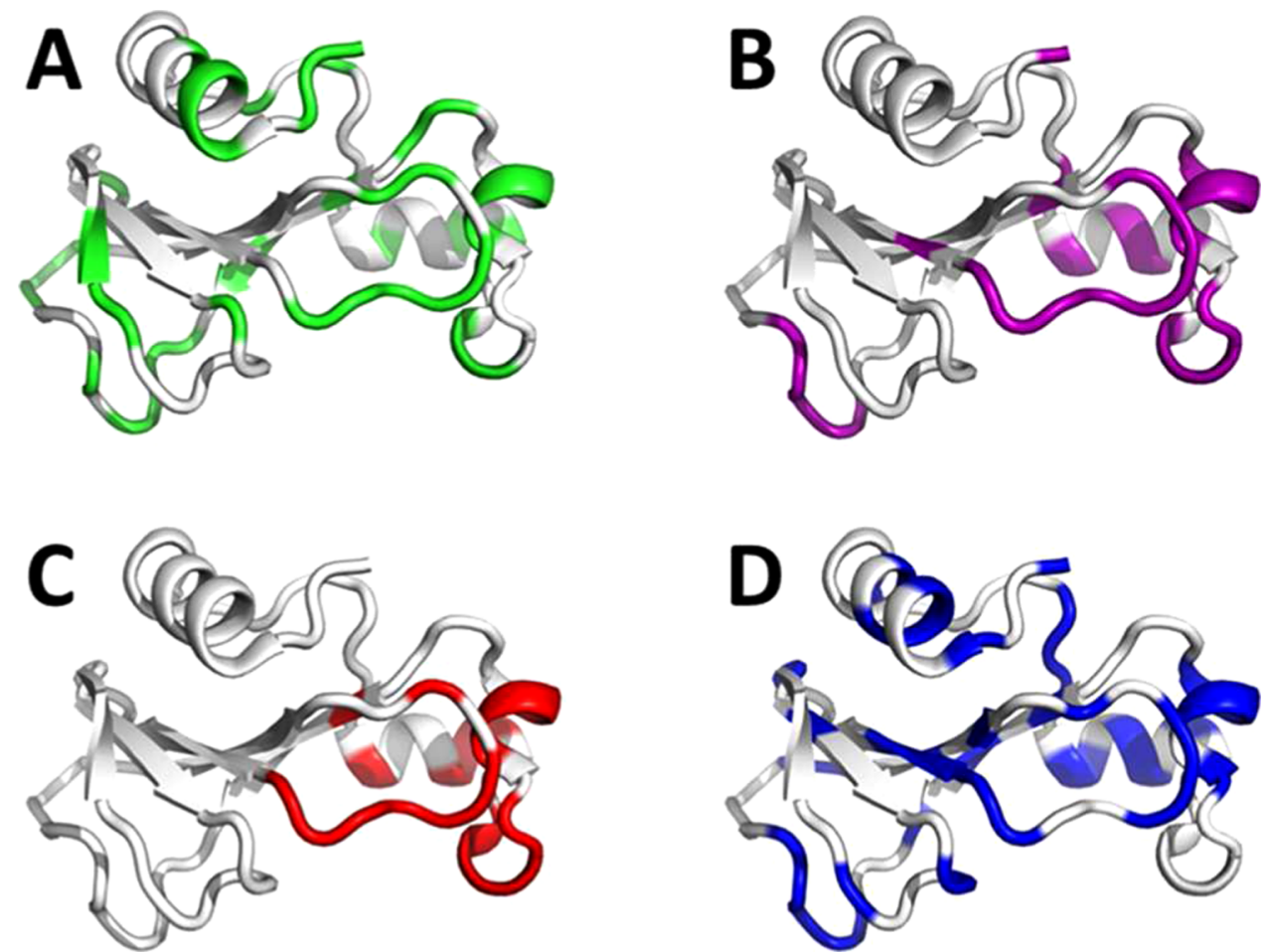

Figure 4. (A) Locations of solvent-exposed backbone amide protons (i.e., protons with a surface-accessible surface area $>0 \AA^{2}$ ) and the positions of amide protons exhibiting a nonlinear relationship between chemical shift and (B) $\mathrm{NaSCN},(\mathrm{C}) \mathrm{NaCl}$, and (D) $\mathrm{Na}_{2} \mathrm{SO}_{4}$ concentration. 
the appearance of typical binding saturation curves, and we therefore hypothesized that the curved responses arise from anion binding, being either a direct effect of binding or an indirect conformational or dynamic change induced by anion binding (discussed in more detail below). We therefore fitted the data at each site to eq $1^{23}$

$$
\begin{aligned}
\Delta \delta_{i}= & \left(-m[\mathrm{~L}]_{i}\right)+\frac{\Delta \delta_{\max }}{2[\mathrm{P}]_{i}}\left[\left([\mathrm{P}]_{i}+K_{\mathrm{d}}+[\mathrm{L}]_{i}\right)\right. \\
& \left.-\left\{\left([\mathrm{P}]_{i}+K_{\mathrm{d}}+[\mathrm{L}]_{i}\right)^{2}-4[\mathrm{P}]_{i}[\mathrm{~L}]_{i}\right\}^{1 / 2}\right]
\end{aligned}
$$

where $\Delta \delta_{i}$ is the observed change in chemical shift, $m$ is the gradient for the linear chemical shift change, $\Delta \delta_{\max }$ is the maximum change in chemical shift upon saturation, $K_{\mathrm{d}}$ is the dissociation constant, and $[\mathrm{P}]_{i}$ and $[\mathrm{L}]_{i}$ are the total concentrations of protein and ligand, respectively. The first term in the equation corresponds to the linear chemical shift change, whereas the second is a standard ligand-binding saturation curve, also known as a binding isotherm. Similar equations have been used previously. ${ }^{5 a, 9 f}$ This equation models the observed chemical shift change as being the sum of a linear term plus one resulting from anion binding. It assumes that the chemical shift change observed at each nucleus is affected by a single binding event, which seems a reasonable approximation given that the chemical shift effects due to binding of anions are likely to be very localized. Most nuclei could be fitted well to this equation. We first tried fitting the shift changes to a simple linear chemical shift change versus anion concentration (the first term in eq 1). Nuclei that fitted poorly to this were then fitted to the complete eq 1 . This resulted in three groups of nuclei: those that fit to a linear equation; those that do not fit well to the linear equation but do fit to the full equation (and therefore have fitted $K_{\mathrm{d}}$ and $\Delta \delta_{\max }$ as well as gradient); and those that do not fit well to either, and were ignored. Fitted parameters are summarized in Tables S1-S18, and some examples and further details are presented in Figure S5.

The good quality of the fitting suggests that this simple model is appropriate, and thus that the three anions studied all show a two-stage effect: site-specific binding with a variable magnitude of chemical shift change and a more generalized linear anion effect at higher concentrations. This result compares well with the DSC results and suggests that the linear effect is the one likely to correspond to the Hofmeister series.

The fitted $K_{\mathrm{d}}$ values cover a wide range of values: $35 \pm 26,52$ \pm 33 , and $18 \pm 20 \mathrm{mM}$ for $\mathrm{NaSCN}, \mathrm{NaCl}$, and $\mathrm{Na}_{2} \mathrm{SO}_{4}$, respectively, over all atoms that fitted to eq 1 (Tables S1-S18). These values report on the binding affinity of the anions at different sites on the protein surface, and a wide range of affinities is expected, varying according to the shape and charge of the protein surface. Barnase is a ribonuclease that attacks RNA phosphate esters and has two surface-exposed binding sites for phosphate ester groups. ${ }^{24}$ One would therefore expect to see some sites with a reasonably high affinity as well as sites with a much lower affinity. With binding affinities in the tens of $\mathrm{mM}$, the binding sites should be saturated by $100-200 \mathrm{mM}$, explaining the change in the shift patterns in this range (Figure 2 ). We now analyze the results from different nuclei in more detail.

${ }^{1} \mathrm{H},{ }^{15} \mathrm{~N}$ HSQC Experiments. Figure 3 shows an enlargement of an area within the ${ }^{1} \mathrm{H},{ }^{15} \mathrm{~N}$ HSQC spectra recorded in the presence of increasing concentrations of thiocyanate, chloride, and sulfate (overlays of the complete spectra are given in Figures S6-S8 for thiocyanate, chloride, and sulfate, respectively). The spectra show that for thiocyanate and to a lesser degree for chloride, backbone amide groups are sensitive to anion concentrations, with some peaks (e.g., L42 and R83) moving quite considerably, whereas for sulfate the peaks do not generally show large positional changes. Figure 4 shows a comparison of the locations of solvent-exposed amide protons in barnase with amide protons that exhibit nonlinear chemical shift changes with increasing thiocyanate, chloride, or sulfate concentration. Most amide groups with nonlinear relationships
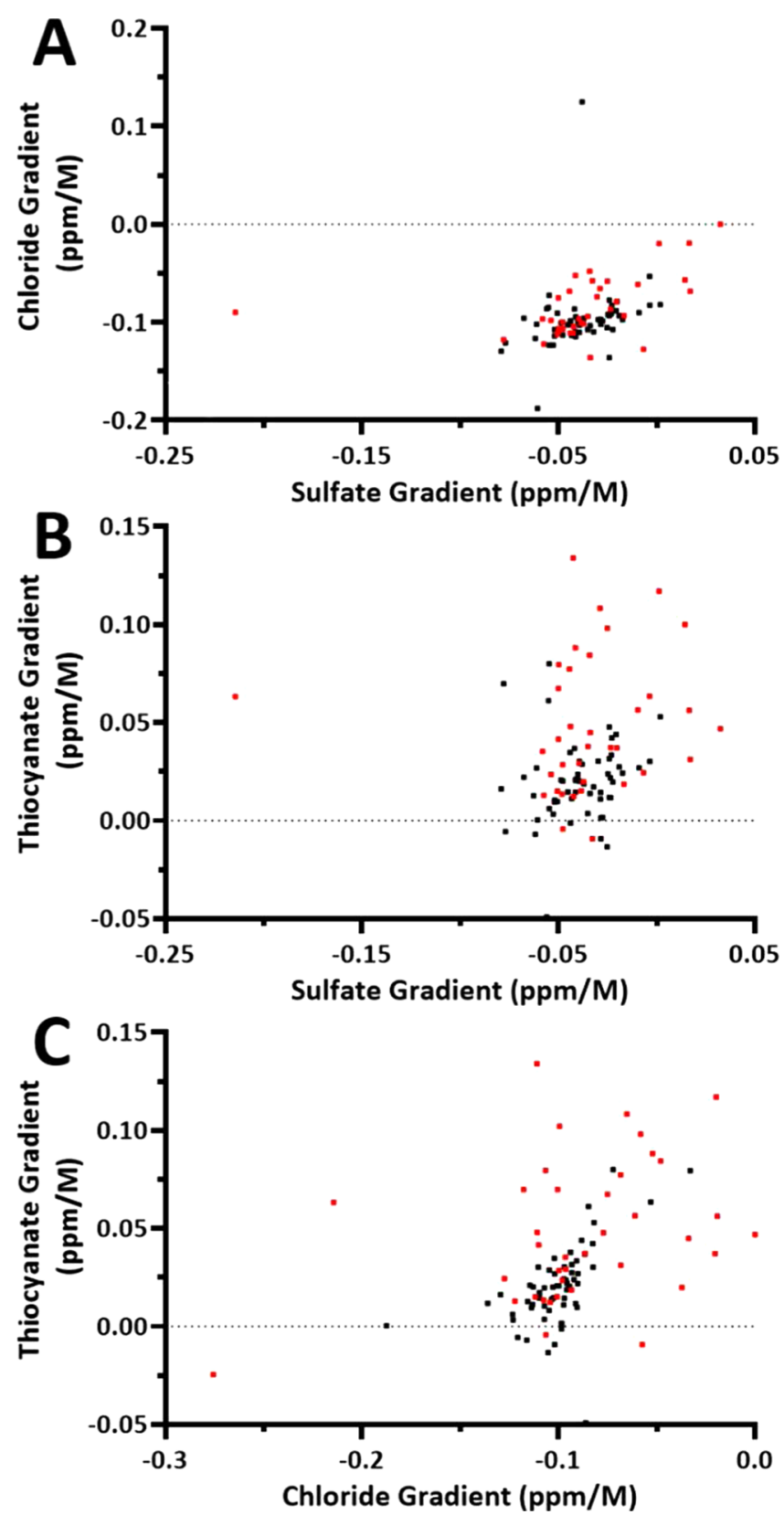

Figure 5. Linear gradients for each salt plotted for all amide protons: (A) chloride vs sulfate gradients, (B) thiocyanate vs sulfate gradients, (C) thiocyanate vs chloride gradients. Black points represent solventinaccessible amide protons, and red points represent solvent-accessible amide proteins as calculated by the naccess software. In $(\mathrm{A})-(\mathrm{C})$, Pearson correlation coefficients $\rho$ are $0.26,0.30$, and 0.57 for buried amide protons, and $0.45,0.08$, and 0.43 for solvent-exposed amide protons. In the majority of cases, these translate into statistically significant correlations using the Fisher transformation. 
are solvent exposed and reach saturation at around 100-250 $\mathrm{mM}$ salt, with fitted $K_{\mathrm{d}}$ values in the range $1-100 \mathrm{mM}$. It is therefore likely that the nonlinear chemical shift changes arise from the binding of anions to the protein surface. It is noteworthy that the three anions studied caused similar relative magnitudes of nonlinear changes in chemical shift (Tables S1, S3, and S5), suggesting that all three interact with the protein backbone and/or affect its conformation in similar ways. This is not the behavior expected in the preferential interaction model.

The nonlinear chemical shift changes have very variable magnitudes at different sites (Tables S1, S3, and S5). For some amide groups, the changes are so large as to produce excessive line broadening resulting in signal disappearance. Very large changes are seen for L42 and R83, with all three anions. These residues are close to the active site, which is set up to bind and stabilize the negative charge of ribonucleotide phosphates, and have a high density of positively charged side chains. It is therefore not surprising that anions should bind preferentially here. It is not possible to position a single anion so that it can bind simultaneously to the backbone amides of both L42 and R83, which are over $7 \AA$ apart. Thus, the large chemical shift changes at both positions suggest either that two anions are binding or that the shift changes are caused by a conformational change rather than by direct binding.

The buried amide protons with nonlinear responses to anion concentration are from residues A30, A46, I51, and I88 for thiocyanate, residue I51 for chloride, and residues Y13, I25, A30, A46, I51, G53, D54, F56, E73, D75, R87, I88, and L89 for sulfate. It is striking that most of these residues are close to the active site and define the same regions for all three anions, implying that anion binding causes similar changes in the structure and/or dynamics of barnase. The effects of sulfate are, however, much more extensive. Sulfate is a large high charge density anion with highly directional electron density, which means it will have a greater ability to distort the structure and dynamics of barnase.

The nonlinear chemical shifts discussed so far arise from anion binding at specific locations in barnase with some additional consequential changes in conformation and/or dynamics at low anion concentrations $(<250 \mathrm{mM})$ and are unrelated to the Hofmeister series. Hofmeister effects are suggested to be associated with the linear shifts seen at higher anion concentrations. For the amide protons, the linear chemical shift changes with increasing anion concentration are largely downfield for thiocyanate and upfield for chloride and sulfate (Figure 5). This is consistent with a relationship between the fitted gradients and Hofmeister effects because sulfate and chloride both stabilize proteins, and thiocyanate at the opposite end of the Hofmeister series destabilizes proteins. ${ }^{7,8,13}$ We suggest that because the chemical shift changes observed are linear and are not saturable, they arise from interactions of the amide groups with solvent rather than with the anions themselves. Moreover, linear effects are observed for nearly all exposed amide groups, and there are not enough anions in solution to produce a general effect such as this. However, the most powerful evidence that the chemical shift changes arise from interactions with solvent comes from a per-residue comparison of the linear shifts caused by the different anions. There is a weak but clear correlation across the protein between the shifts caused by one anion and shifts caused by another (Figure 5), showing that the origin of the shifts is similar for all anions. Downfield chemical shifts in amide protons are normally interpreted as resulting from stronger hydrogen bonding. It therefore appears that thiocyanate causes an increased hydrogen bonding interaction between exposed amides on the protein and solvent, whereas chloride and sulfate both cause a decreased interaction. This is what would be expected if thiocyanate decreases the strength of interactions between one water molecule and another, thereby freeing water molecules to hydrogen bond to protein, whereas chloride and sulfate both strengthen interactions between the water molecules, thereby leaving less free water to hydrogen bond to protein.

HNCO Experiments. Figure 6 shows an expansion of an area within the HNCO spectra recorded in the presence of increasing concentrations of thiocyanate, chloride, and sulfate (overlays of the complete spectra are given in Figures S9-S11). The results show that backbone carbonyl groups are sensitive to anion concentrations: some peaks move considerably for thiocyanate and chloride although they do not move as much for sulfate. The results are similar to those obtained for the ${ }^{1} \mathrm{H},{ }^{15} \mathrm{~N}$ HSQC experiments, in that residues display both linear and nonlinear chemical shift components (Figure 7), and the locations of residues with nonlinear components are similar for the three anions and are mainly on the surface (Figure 8). The fitted binding affinities are consistent with those measured for the ${ }^{1} \mathrm{H},{ }^{15} \mathrm{~N}$ HSQC data. Detailed results are presented in Tables S7-S12.

Carbonyl carbon chemical shifts may change because of cation binding to the carbonyl group, anion binding to the amide group within the same peptide bond, a perturbation in the hydrogen bonding interaction either at the carbonyl oxygen or amide proton, or a conformational change of the backbone. Previous experiments have suggested that sodium cations are excluded from backbone carbonyl groups, making the first explanation unlikely. ${ }^{25}$

We note that the residues showing the largest carbonyl carbon shifts are the same as those showing the largest amide
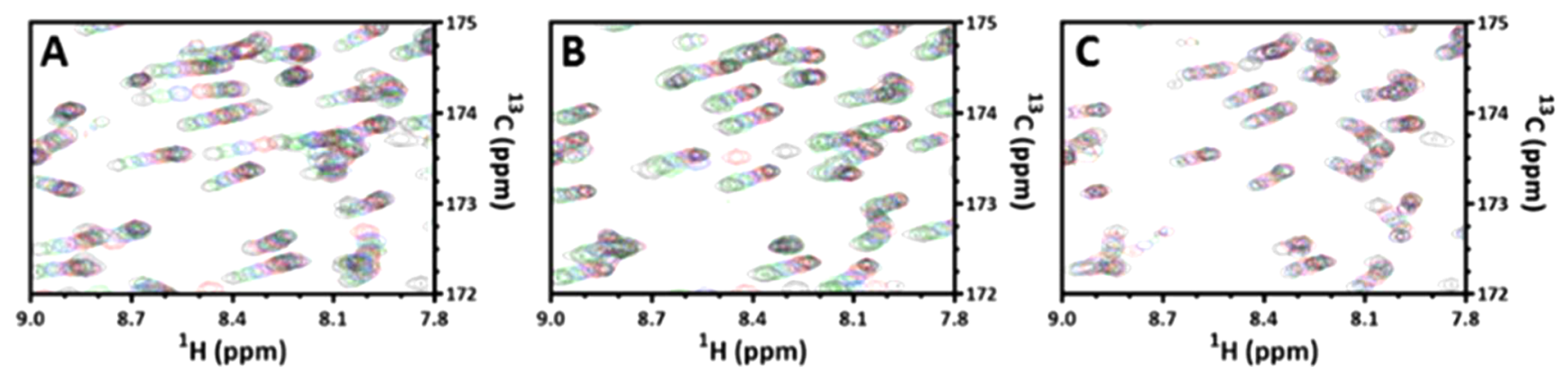

Figure 6. Expansions of a region in the $\mathrm{HNCO}$ spectrum of barnase in the presence of increasing concentrations of $(\mathrm{A}) \mathrm{NaSCN},(\mathrm{B}) \mathrm{NaCl}$, and $(\mathrm{C})$ $\mathrm{Na}_{2} \mathrm{SO}_{4}$ (colors as in Figure 3). 

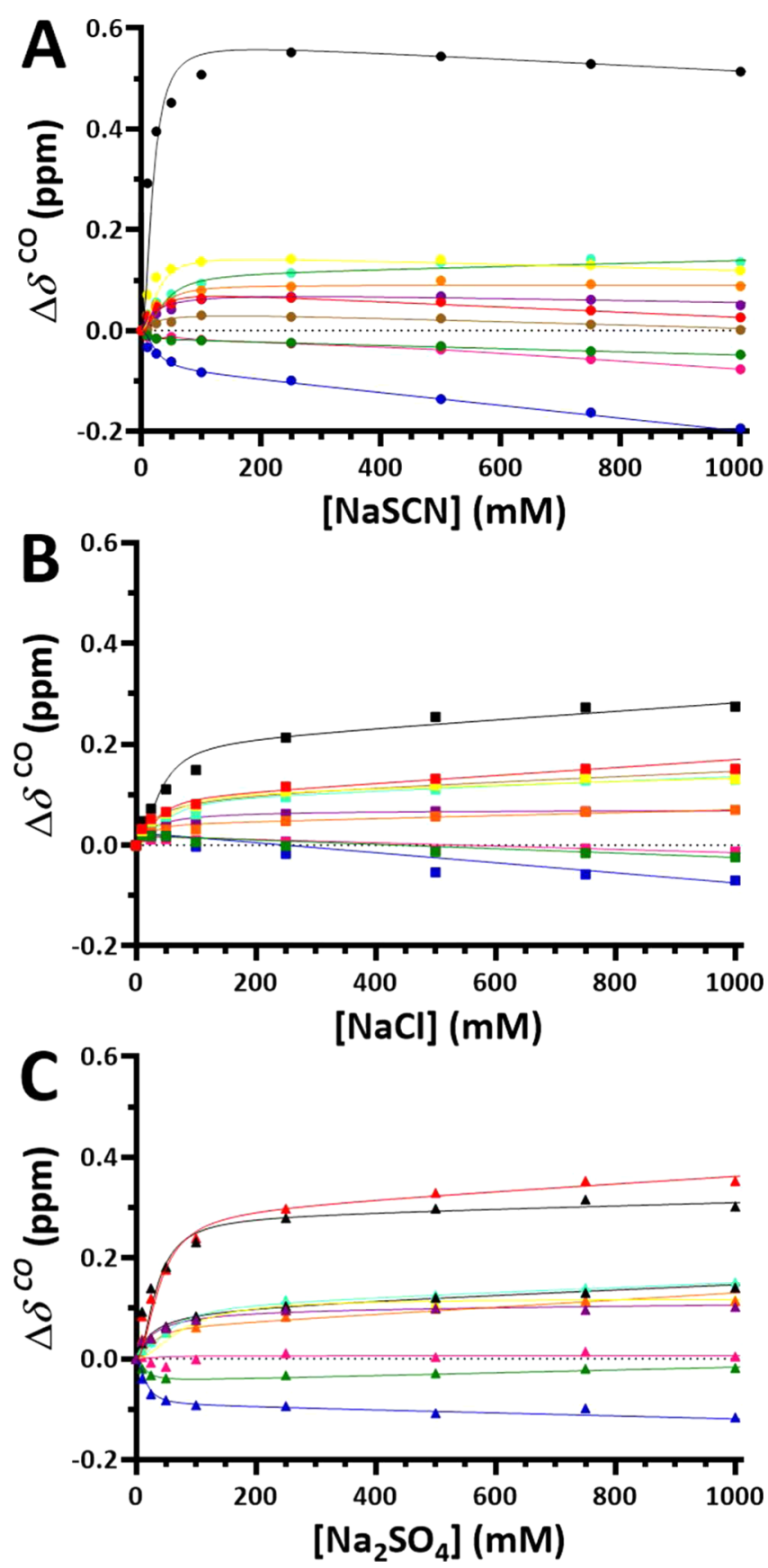

Figure 7. Chemical shift changes for backbone carbonyl carbons in the presence of (A) NaSCN (-), (B) $\mathrm{NaCl}(\boldsymbol{\square})$, and (C) $\mathrm{Na}_{2} \mathrm{SO}_{4}(\boldsymbol{\Delta})$. Symbols represent experimental data, and lines were generated from fitting to eq 1; I25 (aqua), Q31 (orange), L33 (brown), A43 (black), D44 (yellow), G52 (green), N84 (red), R87 (blue), T99 (pink), and D101 (purple).

proton shifts, in particular L42 and R83. This makes the second explanation unlikely and strongly suggests that these chemical shift changes are in both cases due to conformational changes and not to direct anion binding.

${ }^{1} \mathrm{H},{ }^{13} \mathrm{C}$ HSQC Experiments. ${ }^{1} \mathrm{H},{ }^{13} \mathrm{C}$ HSQC spectra with the three anions (Figures S12-S14) show a combination of linear and nonlinear effects, similar to the ${ }^{1} \mathrm{H},{ }^{15} \mathrm{~N}$ HSQC and $\mathrm{HNCO}$ spectra (Tables S13-S18). The results are less complete than for the ${ }^{1} \mathrm{H},{ }^{15} \mathrm{~N}$ HSQC and the $\mathrm{HNCO}$ data because of greater peak overlap and interference from the water signal. We have not attempted to measure signals from aromatic groups. Chemical shifts for $\mathrm{C}-\mathrm{H}$ groups were most sensitive to thiocyanate and chloride and least sensitive to sulfate. Many of the chemical shift changes observed in the thiocyanate and chloride titrations were linear, that is, the curvature was too small to be significant (Figure 9). Exceptions to this trend occurred for aliphatic groups at residues Q2, K27, Q31, V36, A37, N41, L42, D44, I51, S57, and F82 for thiocyanate and Q2, L14, V36, A37, G40, N41, I51, N77, T79, and D93 for chloride. The majority of these residues are close to the active site of barnase, as seen for the amide proton and carbonyl carbon data, confirming preferential binding of the anions close to the positively charged active site. In contrast, the sulfate anion caused widespread nonlinear chemical shift changes.

Titration with sulfate also produced extensive peak broadening, and thus a loss in signal intensity, in both exposed and buried residues, to a much greater extent than seen for chloride or thiocyanate. Figures S1, S16, and S17 show the intensity ratio between $\mathrm{HSQC}$ peaks at 0 and $1000 \mathrm{mM} \mathrm{NaSCN}, \mathrm{NaCl}$, and $\mathrm{Na}_{2} \mathrm{SO}_{4}$, respectively. The largest losses in intensity occurred for $\mathrm{Na}_{2} \mathrm{SO}_{4}$, whereas $\mathrm{NaCl}$ and $\mathrm{NaSCN}$ showed much smaller decreases in intensity during the titration. Sitespecific peak broadening during NMR titrations can arise from a number of factors, which have in common a slowing down of a dynamic exchange process so that it becomes comparable in rate to the chemical shift changes produced by the exchange. ${ }^{26}$ Most commonly, the exchange process is detachment of the ligand. This is very likely to be the reason for the line broadening observed for a small number of highly shifted resonances in the ${ }^{15} \mathrm{~N}$ HSQC titrations discussed above: the off-rate of the ligand becomes comparable to the difference in chemical shift between free and bound species. However, this is unlikely to be the explanation for the peak broadening seen during the sulfate titration because sulfate in general causes the smallest shift changes of the three anions (Figure 9C). Furthermore, the peak broadening induced by sulfate is seen not just for surface residues but also for a large number of buried residues, implying that the explanation is not limited to a surface phenomenon but extends into the interior of the protein. Instead, we propose that the peak broadening is likely to arise from a restriction of internal motions in the protein induced by sulfate. To appear as peak broadening, the dynamics must be slowed to a range similar to the carbon chemical shift differences, which approximates to around $10^{3} \mathrm{~s}^{-1}$. The intramolecular motions in barnase that are closest to this timescale are collective motions typified by interdomain fluctuations. ${ }^{27}$ Thus, we propose that addition of sulfate slows interdomain fluctuations in barnase, this effect being much larger than that caused by chloride or thiocyanate.

A particular interest in the ${ }^{1} \mathrm{H},{ }^{13} \mathrm{C}$ HSQC titrations was whether the low charge density anion thiocyanate $\left(\mathrm{SCN}^{-}\right)$ interacts preferentially with hydrophobic regions. It has been proposed that this could explain Hofmeister effects for such ions, ${ }^{28}$ in contrast to the high charge density anions, which have been shown not to interact with hydrophobic groups. ${ }^{1-3}$ From our experiments, there is no evidence to support this idea. Although nonlinear relationships were seen for methyl groups with thiocyanate, they were also observed for both chloride and sulfate at the same positions. Similarly, the linear chemical shift changes fit the pattern seen for amide proton and carbonyl carbon nuclei in the ${ }^{1} \mathrm{H},{ }^{15} \mathrm{~N}$ HSQC and $\mathrm{HNCO}$ spectra. This constitutes strong evidence against the preferential interaction model. 

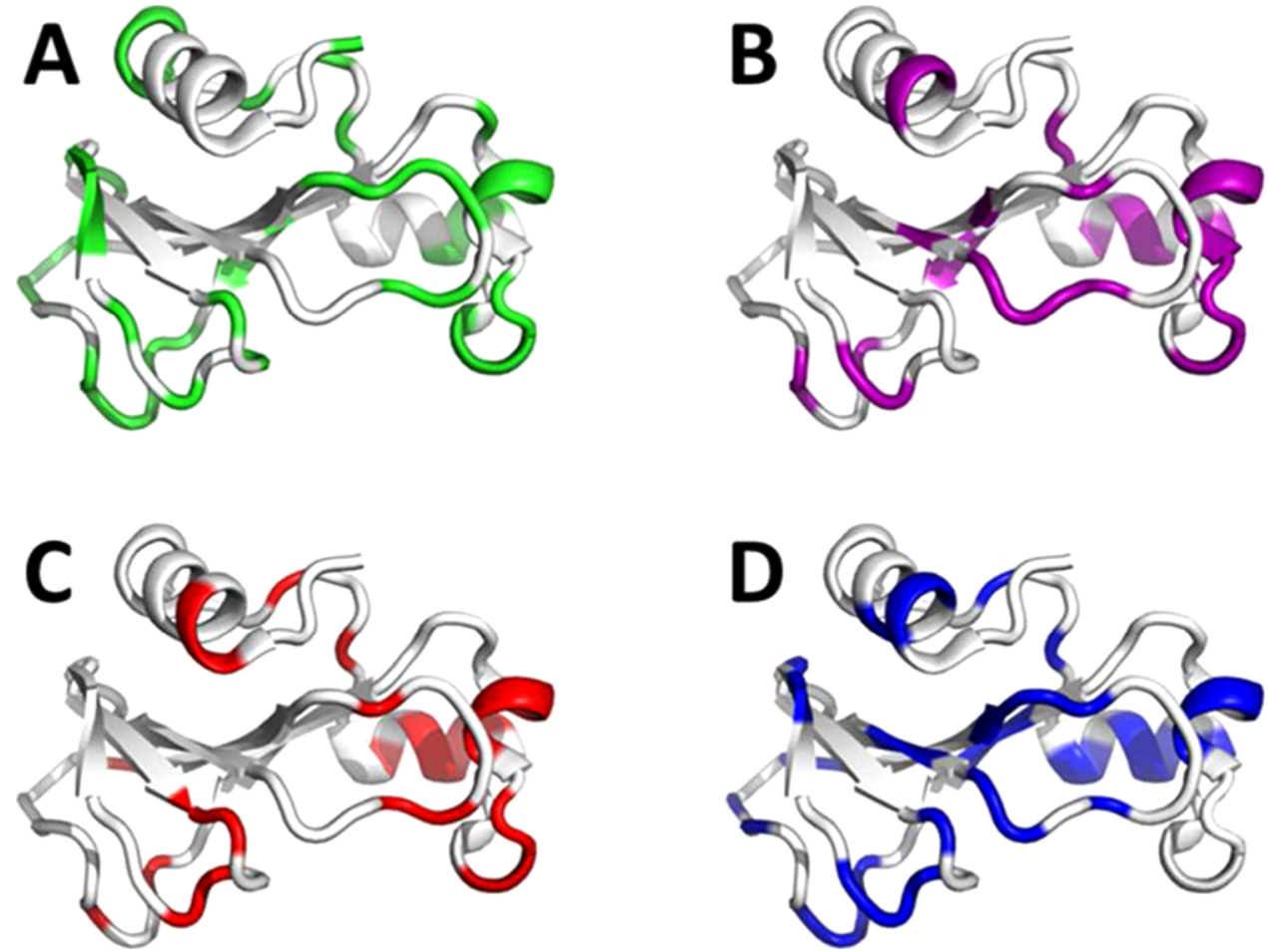

Figure 8. (A) Locations of solvent-exposed backbone carbonyl oxygens (i.e., oxygens with a surface-accessible surface area $>5 \AA^{2}$ ), and the position of carbonyl carbons exhibiting a nonlinear relationship between chemical shift and (B) $\mathrm{NaSCN},(\mathrm{C}) \mathrm{NaCl}$, and (D) $\mathrm{Na}_{2} \mathrm{SO}_{4}$ concentration.

\section{DISCUSSION}

The DSC and NMR results presented here provide a consistent atomic resolution picture of the interactions of anions with barnase. At low concentrations (up to about $250 \mathrm{mM}$ ), all three anions bind at similar sites, particularly in and around the active site, with affinities in the $1-100 \mathrm{mM}$ range. The interactions are mainly with the protein backbone (and presumably with polar side chains, not studied here) and not with hydrophobic regions. These interactions have small effects on protein stability unrelated to the Hofmeister series. Hofmeister effects are manifested at concentrations in the range 100-1000 mM and arise from changes in the way barnase interacts with solvent, which is altered by anion concentration. These findings suggest that the Hofmeister effect cannot be explained in terms of preferential interaction/hydration or an excluded volume effect and make it unlikely that any explanation based on specific interactions of the protein surface with anions can be valid. The nonlinear relationship between anion concentration and chemical shift observed in this work has been previously reported for thiocyanate with elastin-like polypeptide and the thermoresponsive polymer poly $(\mathrm{N}, \mathrm{N}$-diethylacrylamide $) .{ }^{9 f, 15}$ The two-phase behavior characterized here (specific nonHofmeister binding at low concentration, with Hofmeister effects at high concentration) was described previously by us in DSC studies on lysozyme, where we showed that the onset of Hofmeister behavior occurs at different concentrations for different anions (550, 210, and $120 \mathrm{mM}$ for sodium chloride, sodium sulfate, and sodium phosphate, respectively). ${ }^{7,8}$

We propose that the effect of Hofmeister anions on cosolute stability and solubility is due to the ability of the anions to modulate the properties of water around the protein. Kosmotropes (e.g., sulfate) have high charge density. They are therefore effective in ordering water molecules around themselves. It is well established that bound water molecules have very short residence lifetimes, even at the surface of proteins. $^{29}$ Kosmotropes therefore are unlikely to bind individual water molecules for significant lifetimes, but they do lead to an increased ordering of water molecules in their vicinity. In particular, they order the dipoles of water molecules around themselves. ${ }^{30}$ This statement can be rephrased in the language of thermodynamics: The structure of water is a balance between enthalpy (hydrogen bonds, i.e., dipole-dipole interactions), which tends to increase the degree of local order, and entropy, which tends to decrease it. Kosmotropes shift the balance toward an increase in local order, organized around the kosmotrope. The surface of a protein consists of multiple charged/polar and nonpolar chemical species. Optimal solvation of these species requires the surrounding water molecules to be oriented in certain energetically preferred ways. The protein is thus competing with cosolutes (and bulk water) to organize water molecules optimally (an idea originally proposed by Hofmeister). ${ }^{2,6}$ If the cosolute is a kosmotrope, then the protein is outcompeted, with the result that the protein is more poorly solvated. The protein therefore becomes less soluble. A consequence of the poorer solvation is that intramolecular interactions are strengthened, and the protein becomes more stable. (Note that Figure 5 shows that solute concentration affects the chemical shifts not only of exposed amides but also of buried amides to a similar extent: a reflection that a protein in solution is part of a single thermodynamic system and that perturbation of the solvent-exposed face affects the entire protein.) Protein stability and solubility are delicate balances between two large opposing energies. As the concentration of the kosmotrope increases, its effects become stronger. At a salt concentration of $1 \mathrm{M}$, there are roughly 28 water molecules per dissociated ion for salts such as $\mathrm{NaCl}$ and $\mathrm{NaSCN}$ and 19 for $\mathrm{Na}_{2} \mathrm{SO}_{4}$. Thus, there will be many water molecules that are not in the direct solvation sphere of either 

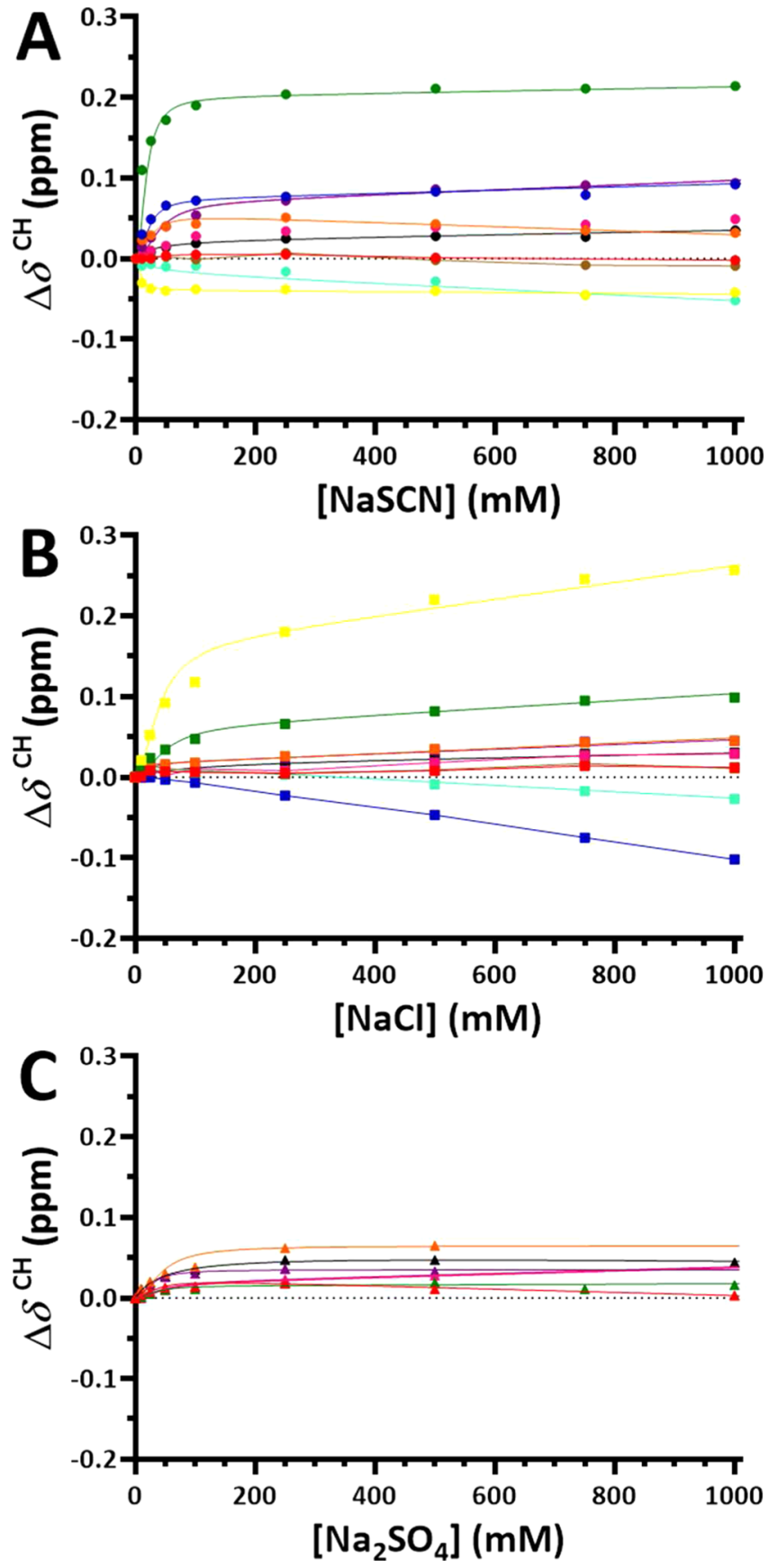

Figure 9. Chemical shift changes for carbon-bound protons acquired from ${ }^{1} \mathrm{H},{ }^{13} \mathrm{C}$ HSQC spectra in the presence of (A) $\mathrm{NaSCN}(\bullet)$, (B) $\mathrm{NaCl}(\boldsymbol{\square})$, and $(\mathrm{C}) \mathrm{Na}_{2} \mathrm{SO}_{4}(\boldsymbol{\Delta})$. Symbols represent experimental data, and lines were generated from fitting to eq 1; K19 H $\varepsilon 2$ (red), A37 $\mathrm{H} \alpha$ (yellow), A37 $\mathrm{H} \beta$ (green), L42 $\mathrm{H} \beta 1$ (blue), I51 $\mathrm{H} \gamma 12$ (orange), E60 H $\alpha$ (purple), L63 H $\gamma$ (pink), R83 H $\beta 2$ (brown), K98 $\mathrm{H} \beta 1$ (aqua), and $\mathrm{K} 108 \mathrm{H} \delta 1$ (black).

protein or cosolute. Nevertheless, the overall thermodynamic balance is enough to affect the solubility and stability of the protein markedly.

Chaotropes (e.g., thiocyanate) have the opposite effect. They have low charge density, and thus organize water molecules poorly. In fact, a chaotrope organizes water molecules less effectively than water itself, which results in the hydrogen bonding network around a chaotrope being less defined than it is in pure water. ${ }^{31}$ Therefore, a protein is better able to organize water molecules around itself in ways that match its solvation requirements when in the presence of chaotropes than in pure water. Chaotropes therefore lead to increased solubility and (following the argument above) decreased stability.

There is another explanation for the effects of Hofmeister anions on protein stability. Protein stability can be expressed as the difference in free energy between a folded protein and an unfolded protein. An unfolded protein has a much larger surface area than a folded protein, and therefore has many more interactions with solvent. Kosmotropes make water dipoles less available for interaction with proteins. They therefore increase the free energy of unfolded proteins more than they do for folded proteins, and so preferentially stabilize folded proteins. These two explanations are different aspects of the same balance of free energies.

The discussion above presents the effect of cosolutes on protein stability as a thermodynamic competition between the hydration of the anion and the hydration of the protein surface. Figure 10 presents data extracted from the literature, showing the relationship between the free energy of anion hydration and protein stability (measured as the change in melting temperature obtained from DSC measurements), for the proteins lysozyme, protein $\mathrm{L}$, protein $\mathrm{L} \mathrm{K} 28 \mathrm{Q}$ and ribonuclease A. ${ }^{3,7,8,13,32}$ The relationship is remarkably consistent, further supporting the argument that the Hofmeister effect on stability is due to the ability of anions to modulate water structure and not due to specific interactions of the ions with protein surfaces or through an excluded volume effect. It has been calculated that anions (particularly the kosmotropes) are preferentially excluded from a protein's apolar surfaces, but the molecular mechanism of the effect has been elusive. ${ }^{33 \mathrm{~b}}$ The discussion here provides a simple explanation, namely, that the anions have lower free energy when fully hydrated by water than they do when bound to the protein. Thus, it is not that they are actively excluded from the protein surface, more that they have a lower free energy when they do not interact directly with the protein. However, as discussed here, the anions do make a number of specific interactions with proteins, with affinities in the millimolar range. Thus, we agree with the thermodynamic analysis of Record's group ${ }^{33}$ and others, ${ }^{5}$ although we see the exclusion of ions from the protein surface as a consequence of

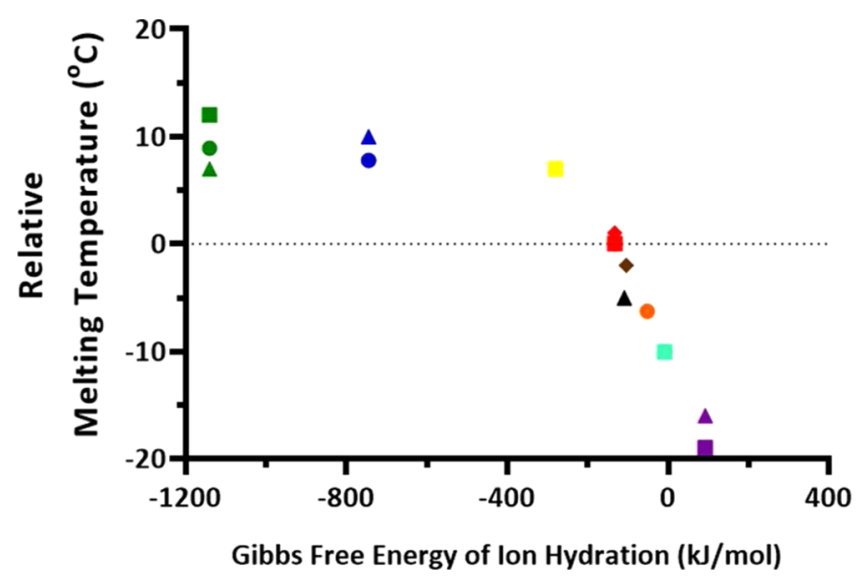

Figure 10. Relative change in protein melting temperature vs Gibbs free energy of ion hydration for lysozyme $(\boldsymbol{\bullet})$, protein $\mathrm{L}(\boldsymbol{\square})$, protein L K28Q (A), and ribonuclease A $(\boldsymbol{)})$ upon addition of $1000 \mathrm{mM}$ phosphate (green), sulfate (blue), fluoride (yellow), chloride (red), nitrate (black), bromide (brown), iodide (orange), perchlorate (aqua), and thiocyanate (purple). In all cases, the counterion was sodium. 
rather than an explanation for the Hofmeister effects. However, we find no evidence for specific interactions with hydrophobic side chains, which calls into question a common model for the effect of osmolytes on protein stability. ${ }^{34}$ Our proposals have features in common with the theories of Lo Nostro and Ninham, ${ }^{35}$ which focus on ion polarizability in the interactions among ions, water, and protein, and with many recent studies that focus on interfacial effects. ${ }^{9 b}$

The advent of terahertz spectroscopy at the turn of the millennium, the increased sensitivity of calorimetric techniques, and improved computing power have expanded the toolbox of techniques available to researchers to study protein and ion hydration. These studies have suggested that hydration layers surrounding ions and proteins are more complicated and extend further than originally determined. ${ }^{36,37}$ Terahertz spectroscopy experiments have highlighted an extended population of water molecules around a number of different proteins that are distinctly different from water molecules in the bulk. ${ }^{38}$ Pressure perturbation calorimetry (PPC) has recently suggested that some ions have hydration layers up to two molecules thick. ${ }^{37}$ All of this work continues to add weight to the argument that it is the modulation of water molecules around proteins that causes the Hofmeister effect.

\section{CONCLUSIONS}

In summary, we have used DSC and NMR to analyze the ability of three Hofmeister anions (thiocyanate, chloride, and sulfate) to modulate barnase thermal stability and to interact with solvent-exposed groups of barnase. NMR experiments showed that all Hofmeister anions were able to interact with barnase at low anion concentrations, and DSC studies showed that at these low concentrations, protein stability is influenced to a small degree that did not follow the Hofmeister series. In fact, the effects are consistent with an "inverse Hofmeister series". ${ }^{\text {5a }}$ Once these sites were saturated, the anions exert their effects by interacting with water rather than interacting with the protein. High charge density anions restrict the ability of water molecules to reorientate their dipole moments. As water reorientations become more restricted with increasing anion concentrations, the protein is less able to be effectively hydrated because the water orientations needed to keep the protein soluble become too high in energy to be populated. This effect reduces protein solubility and increases protein stability. Low charge density anions increase the conformational freedom of water molecules, allowing the protein surface to be hydrated more effectively, which increases protein solubility and decreases protein stability. We suggest that Hofmeister anions exert their effect on protein stability and solubility by altering the ability of water molecules to solvate the protein, rather than through a preferential interaction, preferential hydration, or excluded volume effect.

\section{ASSOCIATED CONTENT}

\section{S Supporting Information}

The Supporting Information is available free of charge on the ACS Publications website at DOI: 10.1021/acsomega.6b00223.

DSC thermograms; change in melting temperature in the presence of $\mathrm{NaCl}$ and $\mathrm{Na}_{2} \mathrm{SO}_{4} ;{ }^{1} \mathrm{H},{ }^{15} \mathrm{~N}$ HSQC spectra; $\mathrm{HNCO}$ spectra; ${ }^{1} \mathrm{H},{ }^{13} \mathrm{C}$ HSQC spectra (Figures $\mathrm{S} 1-$ S17); fitted parameters for amide protons, carbonyl carbons, and carbon protons exhibiting curved and linear behaviors (Tables S1-S18) (PDF)

\section{AUTHOR INFORMATION}

\section{Corresponding Authors}

*E-mail: jordanbye89@gmail.com (J.W.B.).

*E-mail: n.j.baxter@sheffield.ac.uk (N.J.B.).

*E-mail: m.williamson@sheffield.ac.uk (M.P.W.).

\section{Notes}

The authors declare no competing financial interest.

\section{ACKNOWLEDGMENTS}

J.W.B. would like to thank the Engineering and Physical Sciences Research Council (EPSRC) for an EPSRC Postdoctoral Prize Fellowship. We thank Simon Hubbard (University of Manchester) for providing the program naccess and Jeremy Craven (University of Sheffield) for writing the fitting routine.

\section{REFERENCES}

(1) (a) Cox, W. M.; Wolfenden, J. H. Proc. R. Soc. London, Ser. A 1934, 145, 475-488. (b) Tielrooij, K. J.; Garcia-Araez, N.; Bonn, M.; Bakker, H. J. Science 2010, 328, 1006-1009. (c) dos Santos, A. P.; Levin, Y. Faraday Discuss. 2013, 160, 75-87. (d) Collins, K. D.; Wasabaugh, M. W. Q. Rev. Biophys. 1985, 18, 323-422. (e) Marcus, Y. Chem. Rev. 2009, 109, 1346-1370. (f) Jenkins, H. D. B.; Marcus, Y. Chem. Rev. 1995, 95, 2695-2724. (g) Heydweiller, A. Ann. Phys. 1910, 338, 145-185.

(2) Hofmeister, F. Arch. Exp. Pathol. Pharmakol. 1888, 25, 1-30.

(3) Von Hippel, P. H.; Wong, K. J. Biol. Chem. 1965, 240, 39093923.

(4) Von Hippel, P. H.; Schleich, T. Acc. Chem. Res. 1969, 2, 257-265. (5) (a) Zhang, Y.; Cremer, P. S. Proc. Natl. Acad. Sci. U.S.A. 2009, 106, 15249-15253. (b) Ries-Kautt, M. M.; Ducruix, A. F. J. Biol. Chem. 1989, 264, 745-748. (c) Baldwin, R. L. Biophys. J. 1996, 71, 20562063. (d) Curtis, R. A.; Prausnitz, J. M.; Blanch, H. W. Biotechnol. Bioeng. 1997, 57, 11-21. (e) Arakawa, T.; Timasheff, S. N. Biochemistry 1982, 21, 6545-6552. (f) Santoro, M. M.; Liu, Y.; Khan, S. M. A.; Hou, L.-X.; Bolen, D. W. Biochemistry 1992, 31, 52785283.

(6) (a) Kunz, W.; Henle, J.; Ninham, B. W. Curr. Opin. Colloid Interface Sci. 2004, 9, 19-37. (b) Lo Nostro, P.; Ninham, B. W. Chem. Rev. 2012, 112, 2286-2322.

(7) Bye, J. W.; Falconer, R. J. Protein Sci. 2013, 22, 1563-1570.

(8) Bye, J. W.; Falconer, R. J. J. Phys. Chem. B 2014, 118, 4282-4286.

(9) (a) Curtis, R. A.; Ulrich, J.; Montaser, A.; Prausnitz, J. M.; Blanch, H. W. Biotechnol. Bioeng. 2002, 79, 367-380. (b) Jungwirth, P.; Cremer, P. S. Nat. Chem. 2014, 6, 261-263. (c) Collins, K. D. Biophys. Chem. 2012, 167, 43-59. (d) Moelbert, S.; Normand, B.; De Los Rios, P. Biophys. Chem. 2004, 112, 45-57. (e) Timasheff, S. N. Biochemistry 2002, 41, 13473-13482. (f) Rembert, K. B.; Paterova, J.; Heyda, J.; Hilty, C.; Jungwirth, P.; Cremer, P. S. J. Am. Chem. Soc. 2012, 134, 10039-10046.

(10) (a) Jorgensen, L.; Hostrup, S.; Moeller, E. H.; Grohganz, H. Expert Opin. Drug Delivery 2009, 6, 1219-1230. (b) Manning, M. C.; Chou, D. K.; Murphy, B. M.; Payne, R. W.; Katayama, D. S. Pharm. Res. 2010, 27, 544-575. (c) Wang, W. Int. J. Pharm. 2005, 289, 1-30. (d) Bye, J. W.; Platts, L.; Falconer, R. J. Biotechnol. Lett. 2014, 36, 869-875.

(11) (a) Mancinelli, R.; Botti, A.; Bruni, F.; Ricci, M. A.; Soper, A. K. J. Phys. Chem. B 2007, 111, 13570-13577. (b) Omta, A. W.; Kropman, M. F.; Woutersen, S.; Bakker, H. J. Science 2003, 301, 347-349. (c) Batchelor, J. D.; Olteanu, A.; Tripathy, A.; Pielak, G. J. J. Am. Chem. Soc. 2004, 126, 1958-1961. (d) Omta, A. W.; Kropman, M. F.; Woutersen, S.; Bakker, H. J. J. Chem. Phys. 2003, 119, 12457. (e) Zhang, Y.; Cremer, P. S. Annu. Rev. Phys. Chem. 2010, 61, 63-83. (12) (a) Arakawa, T.; Bhat, R.; Timasheff, S. N. Biochemistry 1990, 29, 1914-1923. (b) Figueiredo, A. M.; Sardinha, J.; Moore, G. R.; Cabrita, E. J. Phys. Chem. Chem. Phys. 2013, 15, 19632-19643.

(13) Tadeo, X.; Pons, M.; Millet, O. Biochemistry 2007, 46, 917-923. 
(14) (a) Lund, M.; Vácha, R.; Jungwirth, P. Langmuir 2008, 24, 3387-3391. (b) Lund, M.; Jungwirth, P. Phys. Rev. Lett. 2008, 100, 258105-258109. (c) Rankin, B. M.; Ben-Amotz, D. J. Am. Chem. Soc. 2013, 135, 8818-8821. (d) Rankin, B. M.; Hands, M. D.; Wilcox, D. S.; Fega, K. R.; Slipchenko, L. V.; Ben-Amotz, D. Faraday Discuss. 2013, 160, 255-270.

(15) Rembert, K. B.; Okur, H. I.; Hilty, C.; Cremer, P. S. Langmuir 2015, 31, 3459-3464.

(16) Jolivalt, C.; Böckmann, A.; Riès-Kautt, M. M.; Ducruix, A.; Guittet, E. Biophys. Chem. 1998, 71, 221-234.

(17) (a) Shi, Y.-C.; Prausnitz, J. M.; Blanch, H. W. Biotechnol. Bioeng. 1992, 40, 1155-1164. (b) Shiau, K.-S.; Chen, T.-H. Biotechnol. Bioeng. 1997, 53, 202-206.

(18) Jucovic, M.; Hartley, R. W. Proc. Natl. Acad. Sci. U.S.A. 1996, 93, 2343-2347.

(19) Flores, S. C.; Kherb, J.; Konelick, N.; Chen, X.; Cremer, P. S. J. Phys. Chem. C 2012, 116, 5730-5734.

(20) Cioffi, M.; Hunter, C. A.; Packer, M. J.; Pandya, M. J.; Williamson, M. P. J. Biomol. NMR 2009, 43, 11-19.

(21) Bruylants, G.; Wouters, J.; Michaux, C. Curr. Med. Chem. 2005, 12, 2011-2020.

(22) Ulrich, E. L.; Akutsu, H.; Doreleijers, J. F.; Harano, Y.; Ioannidis, Y. E.; Lin, J.; Livny, M.; Mading, S.; Maziuk, D.; Miller, Z. Nucleic Acids Res. 2007, 36, D402-D408.

(23) Murray, N. J.; Williamson, M. P.; Lilley, T. H.; Haslam, E. Eur. J. Biochem. 1994, 219, 923-935.

(24) Buckle, A. M.; Schreiber, G.; Fersht, A. R. Biochemistry 1994, 33, $8878-8889$.

(25) Kherb, J.; Flores, S. C.; Cremer, P. S. J. Phys. Chem. B 2012, 116, 7389-7397.

(26) Williamson, M. P. Prog. Nucl. Magn. Reson. Spectrosc. 2013, 73, $1-16$.

(27) Wilton, D. J.; Ghosh, M.; Chary, K.; Akasaka, K.; Williamson, M. P. Nucleic Acids Res. 2008, 36, 4032-4037.

(28) Lund, M.; Vrbka, L.; Jungwirth, P. J. Am. Chem. Soc. 2008, 130, $11582-11583$

(29) Halle, B. Philos. Trans. R. Soc., B 2004, 359, 1207-1224.

(30) Hey, J. C.; Smeeton, L. C.; Oakley, M. T.; Johnston, R. L. J. Phys. Chem. A 2016, 120, 4008-4015.

(31) Collins, K. D. Biophys. J. 1997, 72, 65-76.

(32) Tadeo, X.; Lopez-Mendez, B.; Castano, D.; Trigueros, T.; Millet, O. Biophys. J. 2009, 97, 2595-2603.

(33) (a) Pegram, L. M.; Record, M. T. J. Phys. Chem. B 2008, 112, 9428-9436. (b) Pegram, L. M.; Wendorff, T.; Erdmann, R.; Shkel, I.; Bellissimo, D.; Felitsky, D. J.; Record, M. T. Proc. Natl. Acad. Sci. U.S.A. 2010, 107, 7716-7721. (c) Record, M. T.; Guinn, E.; Pegram, L.; Capp, M. Faraday Discuss. 2013, 160, 9-44.

(34) (a) Auton, M.; Rösgen, J.; Sinev, M.; Holthauzen, L. M. F.; Bolen, D. W. Biophys. Chem. 2011, 159, 90-99. (b) Street, T. O.; Bolen, D. W.; Rose, G. D. Proc. Natl. Acad. Sci. U.S.A. 2006, 103, 13997-14002 10.1073/pnas.0606236103.

(35) Parsons, D. F.; Boström, M.; Lo Nostro, P.; Ninham, B. W. Phys. Chem. Chem. Phys. 2011, 13, 12352-12367.

(36) Comez, L.; Lupi, L.; Morresi, A.; Paolantoni, M.; Sassi, P.; Fioretto, D. J. Phys. Chem. Lett. 2013, 4, 1188-1192.

(37) Bye, J. W.; Falconer, R. J. Phys. Chem. Chem. Phys. 2015, 17, 14130-14137.

(38) (a) Bye, J. W.; Meliga, S.; Ferachou, D.; Cinque, G.; Zeitler, J. A.; Falconer, R. J. J. Phys. Chem. A 2014, 118, 83-88. (b) Ebbinghaus, S.; Kim, S. J.; Heyden, M.; Yu, X.; Heugen, U.; Gruebele, M.; Leitner, D. M.; Havenith, M. Proc. Natl. Acad. Sci. U.S.A. 2007, 104, 2074920752. (c) Born, B.; Kim, S. J.; Ebbinghaus, S.; Gruebele, M.; Havenith, M. Faraday Discuss. 2009, 141, 161-173. (d) Wallace, V. P.; Ferachou, D.; Ke, P.; Day, K.; Uddin, S.; Casas-Finet, J.; van der Walle, C. F.; Falconer, R. J.; Zeitler, J. A. Pharm. Biotechnol. 2015, 104, 40254033. 